\title{
Symptom Predictors of Cerebrospinal Fluid Leaks
}

\author{
Kazuhiro Ohwaki, Eiji Yano, Teruyuki Ishii, Shigehiko Takanashi, \\ Tadayoshi Nakagomi
}

\begin{abstract}
Background: Spinal cerebrospinal fluid (CSF) leaks, which are considered a cause of intracranial hypotension, generally do not cause any local symptoms. Although symptoms are key elements for further evaluation, few studies have examined symptom predictors of intracranial hypotension. The aim of this study was to determine what symptoms are predictors of CSF leaks in patients suspected of intracranial hypotension. Methods: We performed radionuclide cisternography in 207 consecutive patients suspected of intracranial hypotension. Intracranial hypotension was suspected when a patient had a history of minor trauma and complained about uncontrolled headache, cranial nerve dysfunction, autonomic dysfunction, or higher brain dysfunction. The leakage of CSF was defined as direct signs of tracer leak into the spinal epidural space or early accumulation of the tracer in the urinary bladder. We obtained information on 16 symptoms commonly reported in previous studies. Results: CSF leaks were observed in 154 cases (74\%). Back pain, limb pain, and limb numbness were inversely associated with CSF leaks ( $\mathrm{p}=0.042, \mathrm{p}=0.045$, and $\mathrm{p}=0.006$, respectively). In logistic regression analysis, diplopia was a positive predictor of CSF leaks (odds ratio [OR], 6.53; 95\% confidence interval [CI], 1.49 to 28.51), whereas limb numbness was a negative predictor (OR, 0.38; 95\% CI, 0.17 to 0.84 ). Of the 21 patients in whom diplopia was present and limb numbness was absent, 20 had CSF leaks (specificity, 98\%; positive predictive value, 95\%). Conclusion: Some symptoms may be helpful in the diagnosis of CSF leaks in patients suspected of intracranial hypotension.
\end{abstract}

RÉSUMÉ: Symptômes prédictifs de fuites du liquide céphalorachidien. Contexte : Les fuites spinales de liquide céphalorachidien (LCR), une cause d'hypotension intracrânienne, ne provoquent généralement pas de symptômes locaux. Bien que les symptômes soient l'élément le plus important motivant une évaluation plus poussée, peu d'études ont examiné les symptômes prédictifs de l'hypotension intracrânienne. Le but de cette étude était de déterminer quels symptômes prédisent les fuites de LCR chez les patients chez qui on soupçonne une hypotension intracrânienne. Méthodes : Nous avons effectué une cisternographie isotopique chez 207 patients consécutifs chez qui on soupçonnait la présence d'une hypotension intracrânienne. On soupçonnait une hypotension intracrânienne quand un patient avait des antécédents de trauma mineur et qu'il se plaignait de céphalée rebelle, de dysfonction de nerfs crâniens, de dysfonction neurovégétative ou de dysfonction cérébrale supérieure. Des signes directs de fuite du marqueur radioactif dans l'espace épidural spinal ou une accumulation précoce du marqueur dans la vessie étaient considérés comme révélateurs d'une fuite de LCR. Nous avons recueilli l'information concernant 16 symptômes communément associés à une fuite de LCR dans des études antérieures. Résultats : Des fuites de LCR ont été observées chez 154 patients (74\%). Des douleurs au dos, aux membres et des engourdissements des membres étaient inversement associés à la présence de fuites de LCR ( $\mathrm{p}=0,042, \mathrm{p}=0,045$ et $\mathrm{p}=0,006$ respectivement). L'analyse de régression logistique a montré que la diplopie était un symptôme prédictif positif des fuites de LCR (RC 6,53; IC à 95\% : 1,49 à 28,51), alors que l'engourdissement au niveau des membres était un symptôme prédictif négatif (RC 0,38; IC à 95\%: 0,17 à 0,84). Parmi les 21 patients qui présentaient une diplopie sans engourdissement au niveau des membres, 20 avaient une fuite de LCR (spécificité de 98\%; valeur prédictive positive de 95\%). Conclusion : Certains symptômes peuvent être utiles dans le diagnostic d'une fuite de LCR chez les patients chez qui on soupçonne une hypotension intracrânienne.

Can. J. Neurol. Sci. 2008; 35: 452-457

Once considered an exceedingly rare disorder, intracranial hypotension has recently been found to be an important cause of persistent headaches. However, the nature of intracranial hypotension remains largely unknown. Spinal cerebrospinal fluid (CSF) leaks may be related to intracranial hypotension. Orthostatic headache is among the most common signs and symptoms in patients suspected of having intracranial hypotension, because CSF is readily absorbed into the spinal epidural space and causes the downward displacement of the brain..$^{1-5}$ In addition, nausea, vomiting, photophobia, diplopia, changes in hearing, and posterior neck pain or stiffness have been commonly reported in previous studies. ${ }^{3,6-10}$ Although the

From the Department of Hygiene and Public Health (KO, EY), Department of Neurosurgery (TI, ST, TN), Teikyo University School of Medicine, Tokyo, Japan. Received October 16, 2007. Final Revisions Submitted February 29, 2008 Correspondence to: Kazuhiro Ohwaki, Department of Hygiene and Public Health, Teikyo University School of Medicine, 2-11-1 Kaga Itabashi, Tokyo 173-8605, Japan. 
Table 1: Differences in predictive variables between patients with and without cerebrospinal fluid leaks

\begin{tabular}{|c|c|c|c|}
\hline & $\begin{array}{l}\text { Patients with CSF } \\
\text { leaks }\end{array}$ & $\begin{array}{l}\text { Patients without } \\
\text { CSF leaks }\end{array}$ & $\mathrm{p}$ \\
\hline Factors & $\mathrm{n}=154$ & $\mathrm{n}=53$ & \\
\hline Female sex & $89(58)$ & $28(53)$ & 0.530 \\
\hline Age, $y$, mean $( \pm S D)$ & $38( \pm 12)$ & $44( \pm 13)$ & 0.010 \\
\hline $\begin{array}{l}\text { Trauma } \\
\text { Whiplash injury } \\
\text { Head injury } \\
\text { Others }\end{array}$ & $\begin{array}{c}114(74) \\
31(20) \\
9(6)\end{array}$ & $\begin{array}{c}34(64) \\
13(25) \\
6(11)\end{array}$ & 0.282 \\
\hline \multicolumn{4}{|l|}{ Symptoms } \\
\hline Headache & $134(87)$ & $41(77)$ & 0.094 \\
\hline Neck pain & $103(67)$ & $39(74)$ & 0.365 \\
\hline Shoulder stiffness & $83(54)$ & $31(58)$ & 0.562 \\
\hline Nausea & $41(27)$ & $15(28)$ & 0.813 \\
\hline Visual disturbance & $40(26)$ & $14(26)$ & 0.950 \\
\hline Tinnitus & $48(31)$ & $11(21)$ & 0.147 \\
\hline Hearing disturbance & $16(10)$ & $6(11)$ & 0.850 \\
\hline Dizziness & $87(56)$ & $31(58)$ & 0.800 \\
\hline Diplopia & $24(16)$ & $3(6)$ & 0.095 \\
\hline Facial dysesthesia & $32(21)$ & $15(28)$ & 0.260 \\
\hline Decreased memory & $57(37)$ & $21(40)$ & 0.735 \\
\hline Indecisiveness & $54(35)$ & $18(34)$ & 0.884 \\
\hline Back pain & $68(44)$ & $32(60)$ & 0.042 \\
\hline Limb pain & $22(14)$ & $14(26)$ & 0.045 \\
\hline Limb numbness & $23(15)$ & $17(32)$ & 0.006 \\
\hline Dysgeusia & $6(4)$ & $4(8)$ & 0.282 \\
\hline Orthostatic & $110(71)$ & $37(70)$ & 0.823 \\
\hline
\end{tabular}

Values are n (\%) unless otherwise stated; CSF - cerebrospinal fluid

precise cause of CSF leaks is unclear, many patients with CSF leaks have experienced minor trauma or unusual strain. "Spontaneous" intracranial hypotension would be clinically suspected when patients complain of typical symptoms such as orthostatic headache, whereas patients with a history of trauma are apt to be suspected of having intracranial hypotension when complaining of a wider variety of symptoms. ${ }^{11}$ These symptoms sometimes become more prominent and life-disturbing than post-traumatic headache. In addition to the unfamiliarity with intracranial hypotension among physicians in general, the unusually varied spectrum of clinical manifestations may contribute to a delay in diagnosis. ${ }^{9}$ Because no objective sign has been identified in relation to intracranial hypotension, it can be diagnosed and comprehended only through subjective symptoms. Although many studies have described symptoms associated with intracranial hypotension, few have examined their relationships with CSF leaks. Increased knowledge of how patients present with intracranial hypotension should enable expeditious and accurate identification of CSF leaks. Therefore, it is valuable to identify reliable symptom predictors of CSF leaks in patients with intracranial hypotension.

Neither diagnostic criteria nor a gold standard have been established to define intracranial hypotension. ${ }^{5}$ Because spinal CSF leaks are thought to cause intracranial hypotension, detecting CSF leaks should be useful in diagnosis. Radionuclide cisternography is particularly useful for identifying CSF leaks and studying CSF circulation. In fact, cisternography often reveals the approximate site of the leak by demonstrating

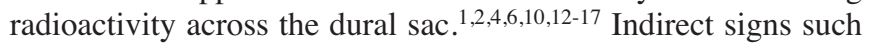
as early accumulation of tracer within the urinary bladder, indicating early absorption into the epidural venous system through an abnormal leak, are also used to diagnose CSF leaks.

The aim of this study was to determine what symptoms are predictors of CSF leaks detected by radionuclide cisternography in patients with a history of minor trauma who were suspected of intracranial hypotension. 


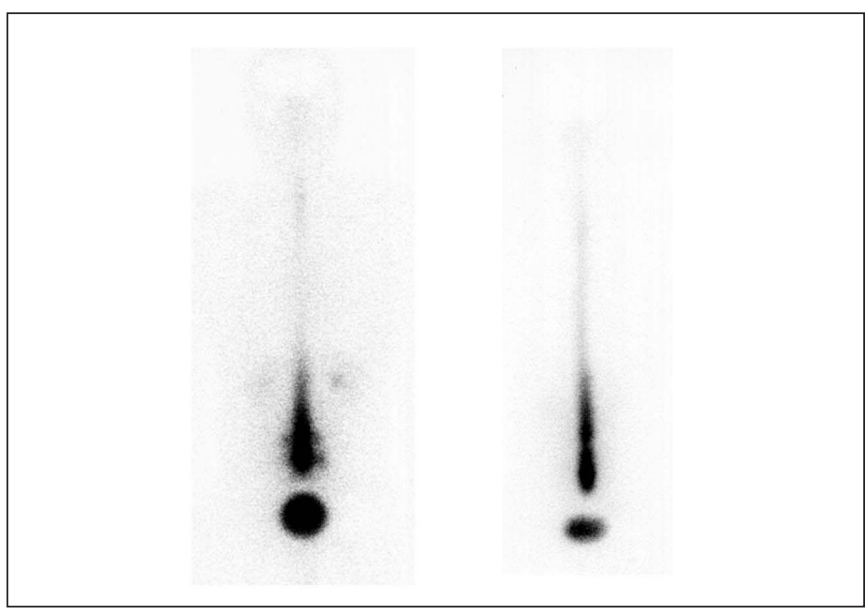

Figure: Radionuclide cisternography two hours after injection of 111Indiethylenetriamine penta-acetic acid demonstrating direct signs of tracer leak into the spinal epidural space (left) or early accumulation of the tracer in the urinary bladder without direct signs of leak (right).

\section{Methods}

The study population consisted of a consecutive group of patients who were suspected of intracranial hypotension and underwent radionuclide cisternography between January 2003 and November 2006. Intracranial hypotension was suspected when a patient had a history of minor trauma and complained about uncontrolled headache, cranial nerve dysfunction, autonomic dysfunction, or higher brain dysfunction. Autonomic dysfunction included fever, abnormal blood-pressure, palpitation, gastrointestinal trouble, nausea, dyshydrosis, and coldness of limbs. Higher brain dysfunction included decreased memory, diminished ability to think or indecisiveness, and loss of concentration. Cisternography was performed mainly because a patient suffered from intolerable and chronic symptoms and was left undiagnosed. All patients' medical records and imaging studies were reviewed. We excluded patients with no history of trauma who underwent radionuclide cisternography $(n=59)$. During the 47-month period under study, 207 patients were identified and assessed retrospectively.

The outcome variable was CSF leaks detected by radionuclide cisternography. Radionuclide cisternography was performed after a lumbar injection of ${ }^{111}$ In-diethylenetriamine penta-acetic acid. Images were obtained shortly after and two, four, and six hours after the injection. Direct signs of tracer leak into the spinal epidural space are always observed with early accumulation of the tracer in the urinary bladder. Thus, leakage of CSF was defined by direct signs of tracer leak into the spinal epidural space or early accumulation of the tracer in the urinary bladder without direct signs of leak (two hours after injection) $)^{1,2,4,6,10,12-17}$ (Figure). One of the authors (TN) reviewed all images independent of subjective symptoms.

The data were coded and recorded in the database. In addition to sex and age, a history of trauma was recorded, including head injury, whiplash injury, or other injuries. Based on previous studies, the following 16 symptoms were selected for analysis: headache, posterior neck pain, shoulder stiffness, nausea, ${ }^{3,6,9,10}$, visual abnormality, ${ }^{8-10}$ diplopia, ${ }^{3,7-10}$ facial dysesthesia, dysgeusia, ${ }^{3,9}$ tinnitus, ${ }^{3,6,10}$ change in hearing, ${ }^{3,9}$ dizziness, ${ }^{6,18}$ decreased memory, diminished ability to think or indecisiveness, ${ }^{6,19}$ back pain, ${ }^{10,18}$ limb pain, ${ }^{3,5,6,9,18,20}$ and limb numbness, ${ }^{5,6,9,18}$ We also asked whether the pain, including headache, neck pain, back pain, and limb pain, worsened after sitting or standing (orthostatic). The study protocol was approved by the internal review board of Teikyo University School of Medicine.

We used chi-square tests or Fisher's exact tests to compare patients with and without CSF leaks for the categorical variables including sex and all symptoms. We performed a $t$-test to assess

Table 2: Results of multiple logistic regression analysis*

\begin{tabular}{lcc}
\hline Variable & Odds ratio & $95 \%$ confidence interval \\
\hline Sex & 0.75 & $0.38-1.49$ \\
Age, per 10 y & 0.81 & $0.62-1.07$ \\
Headache & 2.16 & $0.88-5.29$ \\
Diplopia & 6.53 & $1.49-28.51$ \\
Back pain & 0.57 & $0.28-1.16$ \\
Limb pain & 0.48 & $0.20-1.15$ \\
Limb numbness & 0.38 & $0.17-0.84$ \\
Dysgeusia & 0.34 & $0.08-1.52$ \\
\hline
\end{tabular}

*The following variables were entered $(\mathrm{p}<0.20)$ or removed $(\mathrm{p}<$ 0.20 ) by the stepwise method after forcing sex and age into the model: headache, neck pain, shoulder stiffness, nausea, visual disturbance, tinnitus, hearing disturbance, dizziness, diplopia, facial dysesthesia, decreased memory, indecisiveness, back pain, limb pain, limb numbness, dysgeusia, and orthostatic.

the effect of age. A stepwise multiple logistic regression analysis was performed to select the indicative symptoms predicting CSF leaks and to determine the independent effects of selected predictors. After forcing sex and age to remain in the model, the inclusion and exclusion criteria for the stepwise method were both set at $\mathrm{p}<0.20$ in order to include more variables in the final model, allowing some protection against confounders.

All analyses were performed using the SAS statistical package. A $p$ value of $<0.05$ was accepted as significant. 
Table 3: Accuracy of selected subjective symptoms for the diagnosis of cerebrospinal fluid leaks

\begin{tabular}{|c|c|c|c|c|}
\hline & $\begin{array}{c}\text { CSF } \\
\text { leaks } \\
\text { /total }\end{array}$ & Specificity & Sensitivity & $\begin{array}{c}\text { Positive } \\
\text { predictive } \\
\text { value }\end{array}$ \\
\hline Diplopia (+) and headache (+) & $20 / 22$ & $96 \%$ & $13 \%$ & $91 \%$ \\
\hline Back pain $(-)$, limb pain $(-)$, & $65 / 81$ & $70 \%$ & $42 \%$ & $80 \%$ \\
\hline \multicolumn{5}{|l|}{ limb numbness (-), and dysguesia (-) } \\
\hline Diplopia (+) and limb numbness (-) & $20 / 21$ & $98 \%$ & $13 \%$ & $95 \%$ \\
\hline Six selected symptoms $*$ & $7 / 7$ & $100 \%$ & $5 \%$ & $100 \%$ \\
\hline
\end{tabular}

\section{Results}

The patient group consisted of 90 males $(43 \%)$ and 117 females with an age range of 9 to 76 (mean $40 \pm 13$ ) years. No patient had an obvious underlying connective tissue disorder such as Marfan syndrome or Ehlers-Danlos syndrome.

Of the total participants, 154 (74\%) showed CSF leaks, including direct signs of tracer leak into the spinal epidural space in 124 patients $(60 \%)$ and early accumulation of the tracer in the urinary bladder (without direct signs of leak) in 30 patients (14\%).

The most common symptom was headache $(n=175)$, followed by neck pain $(\mathrm{n}=142)$, dizziness $(\mathrm{n}=118)$, and shoulder stiffness $(n=114)$. As shown in Table 1 , younger age was significantly associated with CSF leaks $(p=0.010)$. None of the symptoms showed a significant positive association with CSF leaks. Although back pain, limb pain, and limb numbness were significantly associated with CSF leaks, the associations were negative: patients with each of those symptoms were less likely to have CSF leaks ( $44 \%$ vs $60 \%, p=0.042 ; 14 \%$ vs $26 \%$, $\mathrm{p}=0.045 ; 15 \%$ vs $32 \% ; \mathrm{p}=0.006$, respectively). None of the objective findings, such as disturbance in eye movement, was observed.

After forcing sex and age to remain in the model, six variables were entered in the stepwise logistic regression analysis (Table 2). The results of the logistic regression analysis indicated that only diplopia was a significant positive predictor of CSF leaks (odds ratio [OR], 6.53; 95\% confidence interval [CI], 1.49 to 28.51). Limb numbness was significantly negatively associated with CSF leaks (OR, 0.38; 95\% CI, 0.17 to $0.84)$.

The results on the symptom mix for CSF leaks demonstrate a positive predictive value of $95 \%$ and a specificity of $98 \%$ for the combination of presence of diplopia and absence of limb numbness (Table 3). All seven cases categorized as high risk for CSF leaks by all selected symptoms actually had CSF leaks.

\section{Discussion}

In this study, we investigated 16 symptoms commonly reported in previous studies in patients with a history of trauma who were suspected of intracranial hypotension. We found no significant positive associations between symptoms and CSF leaks; moreover, back pain, limb pain, and limb numbness were inversely associated with CSF leaks. In stepwise logistic regression analysis, only diplopia was a significant positive predictor of CSF leaks. Limb numbness was an independent negative predictor. The presence of diplopia and absence of limb numbness strongly suggest the existence of CSF leaks in patients suspected of intracranial hypotension. The high specificity for CSF leaks makes them a useful diagnostic tool.

We excluded patients with no history of trauma from the analyses. When trauma is obviously related to the leak, the term traumatic or post-traumatic intracranial hypotension may be appropriate. 11,16 "Spontaneous" intracranial hypotension has often been reported to be distinct from "post-traumatic" intracranial hypotension. . $16,20,21^{\text {Spontaneous intracranial hypo- }}$ tension would be clinically suspected when patients complain of typical symptoms such as orthostatic headache. On the other hand, post-traumatic intracranial hypotension is likely to be suspected when patients complain of a wider variety of symptoms. ${ }^{11}$ Thus, the diagnostic process is more confusing in patients with post-traumatic intracranial hypotension than in those with the spontaneous type. In this study, only diplopia was significantly positively associated with CSF leakage by logistic regression analysis. Patients with some symptoms were less likely to have CSF leaks. This unexpected finding may reflect the inclusion criteria of our study rather than truly signifying protective characteristics. Among them, some symptoms may be positive predictors of CSF leaks in the general population. The results should be interpreted cautiously. We did not analyze patients with no history of trauma separately from those with a 
history of trauma because of the small number $(n=59)$ of the former. In patients with no history of trauma, 45 had CSF leaks (76\%), and only headache was significantly associated with CSF leaks $(93 \%$ vs $64 \%$; $\mathrm{p}=0.014)$.

Magnetic resonance imaging (MRI) has been reported to be of great help in the diagnosis of intracranial hypotension. The MRIs of the head often demonstrate secondary findings of intracranial hypotension such as brain sagging, pachymeningeal enhancement, and engorged venous sinuses. . $3,5,6,9,22$ However, an incomplete understanding of the variability of MRI findings may result in a diagnosis of intracranial hypotension that erroneously excludes patients with normal findings. ${ }^{5}$ Radionuclide cisternography is more valid for this purpose because its direct sign unequivocally indicates the leak point. In addition, typical findings include early accumulation of tracer in the kidneys and bladder, slow ascent along the spinal axis, and a paucity of activity over the cerebral convexities. . $^{1,4,6,10,12-17}$ In most cases, this study will show early accumulation of tracer in the kidneys and bladder. These findings suggest unusually rapid uptake of tracer into the bloodstream through the extensive epidural venous plexus. ${ }^{4,12,15}$ Early accumulation of tracer in the bladder may be associated with lumbar punctures. ${ }^{23}$ In our study, however, excluding patients with early accumulation of tracer in the bladder $(\mathrm{n}=30)$ in the logistic regression did not alter the significance of the variables: diplopia (OR, 5.58; 95\% CI, 1.3523.15) and limb numbness (OR, 0.36; 95\%CI, 0.16-0.83). Our population had a considerable high prevalence of CSF leaks. The definition of CSF leaks in our study, i.e. direct signs of tracer leak into the spinal epidural space or early accumulation of the tracer in the urinary bladder demonstrated by cisternography, may not necessarily indicate generally-recognized "intracranial hypotension". One previous study reported that radionuclide cisternography identifies the location of the CSF leaks in only about two-thirds of patients in whom CT myelography has defined spinal CSF leaks. ${ }^{10}$ From a theoretical perspective, however, radionuclide cisternography may be useful when the diagnosis of intracranial hypotension is in doubt. ${ }^{5}$

In this study, the specificity for CSF leaks of the combination of the presence of diplopia and absence of limb numbness was $98 \%$, whereas the sensitivities of all symptom combinations were low (5-42\%). This may be due in part to our selection of patients. Although the indication for radionuclide cisternography was not based on specific symptoms or symptom combinations, this study population is likely to be enriched in cases with CSF leaks as suggested by their high prevalence (74\%). Therefore, the symptom combinations assessed in this study may not be useful as a screening tool for CSF leaks in the general population. Although a sensitive test is useful to rule out a disease, it is difficult to refute a diagnosis of intracranial hypotension because of the characteristic of varied clinical manifestations. Given that radionuclide cisternography is an invasive evaluation, an alternative test may be desirable to achieve high specificity. A symptom mix with high specificity may be helpful in diagnosing CSF leaks noninvasively.

Several limitations should be considered in the interpretation of these results. First, symptoms used for analysis were obtained through clinical interviews without the use of standardized and validated questionnaires. However, the information on symptoms was obtained before radionuclide cisternography, thus eliminating a possible bias in the design of a retrospective study. Second, the findings of radionuclide cisternography were assessed by one of the authors. Some misclassification of interpretation of radionuclide cisternography seems likely, but any misclassification would be nondifferential for symptoms, because the evaluator did not take symptoms into consideration. Finally, this series was selected from among the patients at one university hospital. However, it is unlikely that only patients with some particular symptoms, such as diplopia, were assessed by radionuclide cisternography. Further well-designed studies based on larger patient populations are required to investigate what symptoms are useful predictors of intracranial hypotension.

Despite these limitations, our findings have some important practical implications. This study showed that some subjective symptoms are an accurate alternative to radionuclide cisternography to assess the presence of CSF leaks. Future research should focus on identifying more useful predictors of CSF leaks in patients suspected of intracranial hypotension.

\section{REFERENCES}

1. Marcelis J, Silberstein SD. Spontaneous low cerebrospinal fluid pressure headache. Headache. 1990;30:192-6.

2. Miyazawa K, Shiga Y, Hasegawa T, Endoh M, Okita N, Higano S, et al. CSF hypovolemia vs intracranial hypotension in "spontaneous intracranial hypotension syndrome". Neurology. 2003;60:941-7.

3. Mokri B, Piepgras DG, Miller GM. Syndrome of orthostatic headaches and diffuse pachymeningeal gadolinium enhancement. Mayo Clin Proc. 1997;72:400-13.

4. Rando TA, Fishman RA. Spontaneous intracranial hypotension: report of two cases and review of the literature. Neurology. 1992;42:481-7.

5. Schievink WI. Spontaneous spinal cerebrospinal fluid leaks and intracranial hypotension. JAMA. 2006;295:2286-96.

6. Chung SJ, Kim JS, Lee MC. Syndrome of cerebral spinal fluid hypovolemia: clinical and imaging features and outcome. Neurology. 2000;55:1321-7.

7. Ferrante E, Savino A, Brioschi A, Marazzi R, Donato MF, Riva M. Transient oculomotor cranial nerves palsy in spontaneous intracranial hypotension. J Neurosurg Sci. 1998;42:177-9.

8. Horton JC, Fishman RA. Neurovisual findings in the syndrome of spontaneous intracranial hypotension from dural cerebrospinal fluid leak. Ophthalmology. 1994;101:244-51.

9. Schievink WI. Misdiagnosis of spontaneous intracranial hypotension. Arch Neurol. 2003;60:1713-8.

10. Schievink WI, Meyer FB, Atkinson JL, Mokri B. Spontaneous spinal cerebrospinal fluid leaks and intracranial hypotension. J Neurosurg. 1996;84:598-605.

11. Shinonaga M, Suzuki S. Diagnosis and treatment of traumatic intracranial hypotension (cerebrospinal fluid hypotension) [in Japanese]. Neurotraumatology. 2003;26:98-102.

12. Ali SA, Cesani F, Zuckermann JA, Nusynowitz ML, Chaljub G. Spinal-cerebrospinal fluid leak demonstrated by radiopharmaceutical cisternography. Clin Nucl Med. 1998;23:152-5.

13. Benamor M, Tainturier C, Graveleau P, Pierot L. Radionuclide cisternography in spontaneous intracranial hypotension. Clin Nucl Med. 1998;23:150-1.

14. Kong DS, Park K, Nam do H, Lee JI, Kim JS, Eoh W, et al. Clinical features and long-term results of spontaneous intracranial hypotension. Neurosurgery. 2005;57:91-6.

15. Molins A, Alvarez J, Sumalla J, Titus F, Codina A. Cisternographic pattern of spontaneous liquoral hypotension. Cephalalgia. 1990;10:59-65.

16. Moriyama E, Ogawa $\mathrm{T}$, Nishida A, Ishikawa $\mathrm{S}$, Beck $\mathrm{H}$. Quantitative analysis of radioisotope cisternography in the diagnosis of intracranial hypotension. J Neurosurg. 2004;101: 421-6. 
17. Renowden SA, Gregory R, Hyman N, Hilton-Jones D. Spontaneous intracranial hypotension. J Neurol Neurosurg Psychiatry. 1995;59:511-5.

18. Mokri B. Spontaneous low cerebrospinal pressure/volume headaches. Curr Neurol Neurosci Rep. 2004;4:117-24.

19. Hong M, Shah GV, Adams KM, Turner RS, Foster NL. Spontaneous intracranial hypotension causing reversible frontotemporal dementia. Neurology. 2002;58:1285-7.

20. Schievink WI. Spontaneous spinal cerebrospinal fluid leaks: a review. Neurosurg Focus. 2000;9:e8.
21. Schievink WI, Ebersold MJ, Atkinson JL. Roller-coaster headache due to spinal cerebrospinal fluid leak. Lancet. 1996;347:1409.

22. Schievink WI, Maya MM, Louy C. Cranial MRI predicts outcome of spontaneous intracranial hypotension. Neurology. 2005;64:1282-4.

23. Halaç M, Albayram S, Ceyhan E, Ozer H, Dogan I, Sager S, et al. Is early bladder activity in radionuclide cisternography an indirect sign of spontaneous intracranial hypotension or sequence of lumbar puncture? Clin Nucl Med. 2007;32:850-3. 